\title{
Hematopoietic Aging Biomarkers in Peromyscus leucopus Mice
}

Zenghua Lin ${ }^{1,2}$, Sachiko Kajigaya ${ }^{1}$, Xingmin Feng ${ }^{1}$, Jichun Chen ${ }^{1^{*}}$ and Neal S Young ${ }^{1}$

${ }^{1}$ Hematology Branch, National Heart, Lung, and Blood Institute, National Institutes of Health, Bethesda, MD USA

${ }^{2}$ Hematology Department, Affiliated Hospital of Nantong University, Nantong, Jiangsu, China

"Corresponding author: Jichun Chen, Hematology Branch, National Heart, Lung, and Blood Institute, National Institutes of Health, Bethesda, MD USA, Tel: 301-496-2632; Fax: 301-496-8396; E-mail: chenji@nhlbi.nih.gov

Received date: January 10, 2017; Accepted date: February 03, 2017; Published date: February 06, 2017

Copyright: ( 2017 Lin Z, et al. This is an open-access article distributed under the terms of the Creative Commons Attribution License, which permits unrestricted use, distribution, and reproduction in any medium, provided the original author and source are credited.

\section{Abstract}

We analyzed hematopoietic phenotypes in Peromyscus leucopus (PL) mice at young (2-9 months), middle (22-23 months) and old (33-46 months) ages aimed at characterizing age-associated changes in this unique rodent species. We found a significantly higher number of monocytes in old PL mice in peripheral blood, and higher proportions of $\mathrm{CD}_{4} 4^{+}$cells in blood, spleen and bone marrow in old PL mice than in middle and young counterparts. We conclude that elevated blood monocyte counts and up-regulated hematopoietic cell CD44 expression are two useful aging biomarkers for PL mice.

\section{Introduction and Methods}

Peromyscus leucopus (PL) mice are the most populous rodent species that reside in northeastern United States [1]. These animals, nicknamed "white-footed" mice, have distinctive high agility and long lifespans and are taxonomically distant from the frequently-used laboratory mice Mus. musculus (MM) [2-5]. Relative to MM mice, PL mice have fewer platelets and more monocytes [6] and their peripheral blood mononuclear cells have drastically shorter telomeres [7]. The characteristic short telomere and long lifespan in PL mice provide an interesting combination that favors the utility of PL mice as a potential model for aging studies.

Age-related phenotypic changes have been well studied in MM mouse models. Aging was found to cause hematopoietic lineage bias toward myeloid cells [8]. One specific change with age is the expression of CD44, a transmembrane glycoprotein present on the surface of many cell types. Proportions of $\mathrm{CD} 44^{+}$cells are significantly higher in CD4 and CD8 T cells in old mice, which correspond to memory T cell accumulation [9-11] and gamma interferon (IFN- $\gamma$ )-producing $\mathrm{T}$ cell enrichment [12]. Changes in CD44 expression have also been described in other species [13,14]. Age-associated increase in CD $44^{+}$ CD4 cells are found in the spleen of Dark Agouti rats [15]. In rat aorta endothelium, CD44 expression increases in an age-dependent fashion [16].

In the current study, we obtained PL mice from Peromyscus Genetic Stock Center (PGSC) at the University of South Carolina (Columbia, SC) to study age-associated changes in hematopoietic tissues. The PL mouse stock was originated from 38 founders captured near Linville Fall, North Carolina following restricted random breeding in captivity avoiding sister-brother mating [17]. Young (2-9 months) and middleage (22-23 months) PL mice were produced at National Institutes of Health from breeders obtained from PGSC, while old PL mice (33-46 months) were originally obtained from PGSC at young age. All animal studies were approved by the Animal Care and Use Committee at the National Heart, Lung, and Blood Institute.

Blood was collected from retro-orbital sinus and complete blood counts (CBCs) were analyzed using a HemaVet 950 analyzer (Drew
Scientific, Inc. CT). Mice were euthanized by $\mathrm{CO}_{2}$ inhalation from a compressed source. Bone marrow (BM) cells were extracted from bilateral tibiae and femurs, while spleen single cell suspension was obtained by homogenizing the spleen with a Kimble tissue grinder. BM and spleen cells were filtered through $95 \mu \mathrm{M}$ nylon mesh and counted using a Vi-Cell counter (Coulter Cooperation, FL). Red blood cells (RBCs) in blood, BM, and spleen cells were lysed with ACK lysing buffer. Nucleated cells were stained with allophycocyanin (APC)conjugated anti-mouse CD44 (clone 1M7) antibody (BD Bioscience, San Diego, CA) on ice for 30 minutes. Stained cells were acquired and analyzed on FACSCanto II flow cytometer using the FACSDiva software (Becton Dickson, San Diego CA). Data from CBC and flow cytometry were analyzed by GraphPad Prism 6 statistical software through variance analyses and multiple comparisons, and were shown as means with standard errors.

\section{Results and Discussion}

A significant change we observed was a higher number of circulating monocytes in old PL mice $\left(0.46 \pm 0.07 \times 10^{9} / \mathrm{L}\right)$ relative to young $\left(0.26 \pm 0.06 \times 10^{9} / \mathrm{L}\right)$ and middle-age $\left(0.26 \pm 0.07 \times 10^{9} / \mathrm{L}\right)$ animals, suggesting a potential age-related hematopoietic skewing toward myeloid lineage (Figure 1A). There were no age effects on red blood cells, white blood cells, neutrophils, lymphocytes, or platelets (Figure 1A). Our observation was consistent with age-related myeloid lineage skewing reported in the MM mouse model, in which aging is associated with increased self-renewal and reduced lymphoid potential in hematopoietic stem cells [8]. In human studies, aging is also associated with higher blood monocyte counts with a specific expansion of the more mature non-classical monocytes [18]. In elderly individuals, $\mathrm{CD} 34^{+} \mathrm{CD} 38^{+} \mathrm{CD} 90^{-} \mathrm{CD} 45 \mathrm{RA}^{+/-} \mathrm{CD} 10^{-}$and $\mathrm{CD} 34^{+} \mathrm{CD} 33^{+}$ myeloid progenitor cells persisted while $\mathrm{CD} 34^{+} \mathrm{CD} 38^{+} \mathrm{CD} 90^{-} \mathrm{CD} 45 \mathrm{RA}$ ${ }^{+} \mathrm{CD} 10^{+}$and $\mathrm{CD} 34^{+} \mathrm{CD} 19^{+}$B-lymphoid progenitor cells decrease, indicating age-associated lineage bias toward myeloid differentiation $[19,20]$. Thus, increased monocytes with enhanced myeloid differentiation is a shared aging biomarker. 


\section{A}
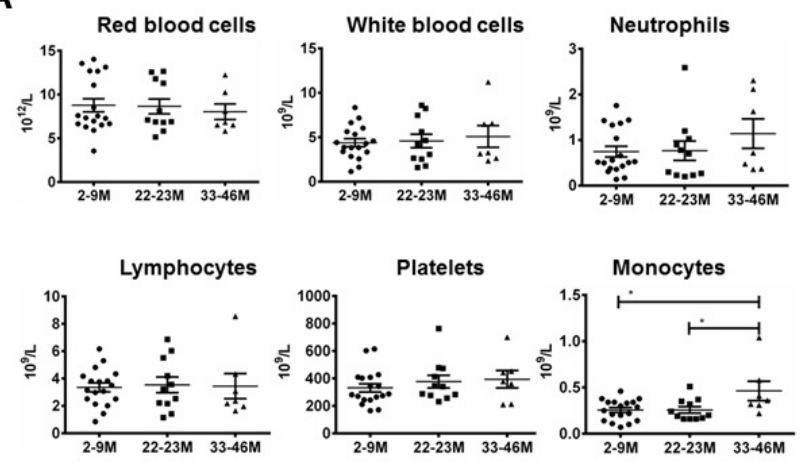

B
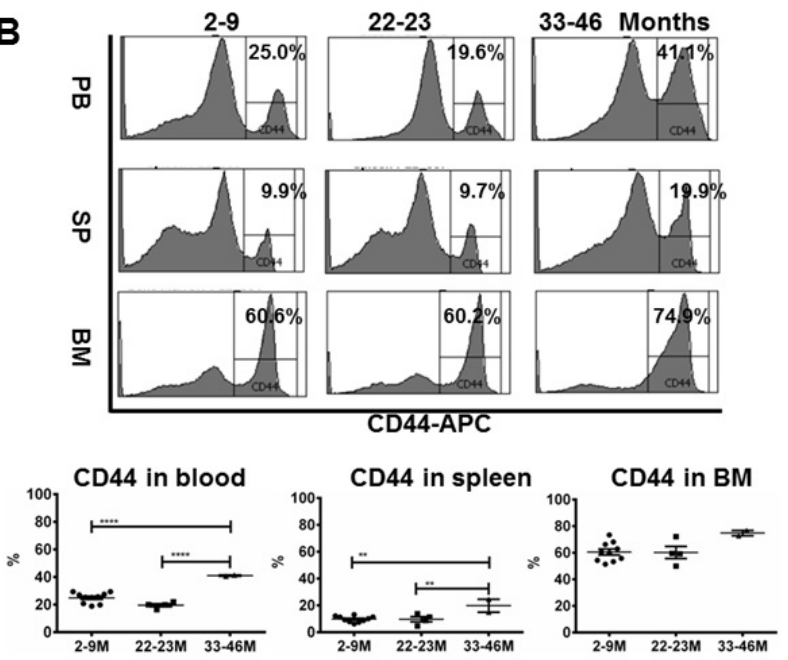

Figure 1: Age associated changes in hematopoietic tissues in Peromyscus leucopus mice. Young (2-9 months, $\mathrm{N}=18)$, middle (22-23 months, $\mathrm{N}=11)$ and old (33-46 months, $\mathrm{N}=7$ ) PL mice were bled from orbital sinus to measure complete blood counts and were then euthanized to extract cells from spleen and BM. (A) There were no changes with age in red blood cells, white blood cells, neutrophils, lymphocytes or platelets but there was a significantly higher number of monocytes in old than in young and middle-age animals. (B) Anti-mouse CD44 antibody was able to stain positive cell populations in peripheral blood, spleen, and BM in PL mice. The proportions of $\mathrm{CD} 44^{+}$cells were significantly higher in old than in young and middle-age $\mathrm{PL}$ mice. ${ }^{*}, \mathrm{P}<.05 ;{ }^{* *}, \mathrm{P}<.01$; ${ }^{* * *}, \mathrm{P}<$. 0001 .

Another change we observed in old PL mice was an increase in the proportion of $\mathrm{CD} 44^{+}$cells in nucleated cells from peripheral blood $(25.0 \pm 2.0 \%, 19.6 \pm 2.6 \%$ and $41.1 \pm 2.9 \%$ for young, middle and old animals), spleen $(9.9 \pm 1.9 \%, 9.7 \pm 2.5 \%$ and $19.9 \pm 2.8 \%)$, and $\mathrm{BM}$ $(60.7 \pm 4.4 \%, 60.2 \pm 5.7 \%$ and $74.9 \pm 6.4 \%$, Figure $1 \mathrm{~B})$. In general, the proportion of $\mathrm{CD} 44^{+}$cells was $\mathrm{BM}>$ peripheral blood $>$ spleen regardless of age (Figure 1B). Age difference in CD44 expression was statistically significant in peripheral blood $(\mathrm{P}<0.0001)$ and spleen $(\mathrm{P}<0.01)$, and was marginally significant in the $\mathrm{BM}(\mathrm{P}<0.07)$. Our finding of agerelated CD44 up-regulation in PL mice was in agreement with observations from MM and other animal models. The utility of increased CD44 expression as an aging biomarker is originally characterized in the MM mouse models [9-12]. In a rat model of experimental autoimmune encephalomyelitis (EAE), increased proportion of splenic $\mathrm{CD} 44^{+} \mathrm{CD} 4^{+} \mathrm{T}$ cells is observed in aged rats, leading to entrapping of activated $\mathrm{CD} 4^{+}$cells in the spleen to restrict EAE development [15]. In a burn-associated wound-healing rat model, CD44 expression on the wound bed is significantly increased in aged rats relative to young rats, which correlates to a delayed wound healing [21]. In aging endothelial cells, epigenetic activation of CD44 expression leads to de-methylation in the promoter regions of the CD44 gene to cause high CD44 expression on cell surface that increases adhesion to monocytes [22]. Thus, age-related CD44 upregulation not only serves as a phenotypic marker but also exerts interference with normal cellular activities. We were unable to pinpoint age-related CD44 up-regulation to specific hematopoietic cell types in PL mice because antibodies (such as CD3, CD4, and CD8) specific for $\mathrm{MM}$ and human do not recognize hematopoietic cells from PL mice [6].

We also examined BM cellularity and morphology in PL mice but found no difference among the three age groups. BM cells from PL mice were capable of forming hematopoietic colonies when cultured in vitro in MethoCult media supplemented with hematopoietic cytokines for MM animals, however, the number of colony-forming cells was few, especially in young mice, and the time of colony formation was delayed in PL mice (Data not shown). A possible explanation is that hematopoietic cytokines and their receptors might be different between MM and PL mice.

Despite shared features of appearance, PL mice differ drastically from MM mice in their higher physical agility [17], longer lifespan [4], and shorter telomeres [7]. PL mice belong to Genus Peromyscus of Subfamily Sigmodontinae while MM mice belong to Genus Mus of Subfamily Murinae in the taxonomic hierarchy, which means that these two species have been separated from each other for millions of years.

In summary, we identified two aging biomarkers in PL mice: 1) elevated circulating monocytes; and 2) up-regulated CD44 expression on hematopoietic cells. Both biomarkers were detected at old age of 33-44 months, not at middle age of 22-23 months. The delayed onset of both biomarkers in PL mice, relative to those in conventional MM mice, was likely related to the long lifespans in PL mice.

\section{Acknowledgments}

This work was supported by National Heart, Lung, and Blood Institute Intramural research funds, and by a scholarship from Affiliated Hospital of Nantong University to Dr. Zenghua Lin.

\section{References}

1. Joyner CP, Myrick LC, Crossland JP, Dawson WD (1998) Deer Mice As Laboratory Animals. ILARJ 39: 322-330.

2. Burger J, Gochfeld M (1992) Survival and reproduction in Peromyscus leucopus in the laboratory: viable model for aging studies. Growth Dev Aging 56: 17-22.

3. Cohen BJ, Cutler RG, Roth GS (1987) Accelerated wound repair in old deer mice (Peromyscus maniculatus) and white-footed mice (Peromyscus leucopus). J Gerontol 42: 302-307.

4. Sacher GA, Hart RW (1978) Longevity, aging and comparative cellular and molecular biology of the house mouse, Mus musculus, and the whitefooted mouse, Peromyscus leucopus. Birth Defects Orig Artic Ser 14: 71-96. 
Citation: Lin Z, Kajigaya, Feng X, Chen J, Young NS (2017) Hematopoietic Aging Biomarkers in Peromyscus leucopus Mice. J Aging Sci 5: 169. doi:10.4172/2329-8847.1000169

Page 3 of 3

5. Steger RW, Peluso JJ, Huang HH, Hodson CA, Leung FC, et al. (1980) Effects of advancing age on the hypothalamic-pituitary-ovarian axis of the female white-footed mouse (Peromyscus leucopus). Exp Aging Res 6: 329-339.

6. Sun Y, Desierto MJ, Ueda Y, Kajigaya S, Chen J, et al. (2014) Peromyscus leucopus mice: a potential animal model for haematological studies. Int J Exp Pathol 95: 342-350.

7. Zhao X, Ueda Y, Kajigaya S, Alaks G, Desierto MJ, et al. (2015) Cloning and molecular characterization of telomerase reverse transcriptase (TERT) and telomere length analysis of Peromyscus leucopus. Gene 568: 8-18.

8. Sudo K, Ema H, Morita Y, Nakauchi H (2000) Age-associated characteristics of murine hematopoietic stem cells. J Exp Med 192 1273-1280.

9. Ernst DN, Weigle WO, Noonan DJ, McQuitty DN, Hobbs MV (1993) The age-associated increase in IFN-gamma synthesis by mouse CD8+ T cells correlates with shifts in the frequencies of cell subsets defined by membrane CD44, CD45RB, 3G11, and MEL-14 expression. J Immunol 151: 575-587.

10. Bloom ET, Mostowski HS, Horvath JA (1994) Does the age-related change in CD44-defined T-cell subsets have functional significance for cytotoxic T lymphocyte generation. Immunol Lett 40: 251-258.

11. Barrat F, Haegel H, Louise A, Vincent-Naulleau S, Boulouis HJ, et al. (1995) Quantitative and qualitative changes in CD44 and MEL-14 expression by $\mathrm{T}$ cells in C57BL/6 mice during aging. Res Immunol 146 23-34.

12. Engwerda CR, Fox BS, Handwerger BS (1996) Cytokine production by T lymphocytes from young and aged mice. J Immunol 156: 3621-2630.

13. Stevens JW, Kurriger GL, Carter AS, Maynard JA (2000) CD44 expression in the developing and growing rat intervertebral disc. Dev Dyn 219 381-390.
14. Hellström M, Johansson B, Engström-Laurent A (2006) Hyaluronan and its receptor CD44 in the heart of newborn and adult rats. Anat Rec A Discov Mol Cell Evol Biol 288: 587-592.

15. Djikić J, Nacka-Aleksić M, Pilipović I, Kosec D, Arsenović-Ranin N, et al. (2015) Age-related changes in spleen of Dark Agouti rats immunized for experimental autoimmune encephalomyelitis. J Neuroimmunol 278: 123-135

16. Mun GI, Boo YC (2010) Identification of CD44 as a senescence-induced cell adhesion gene responsible for the enhanced monocyte recruitment to senescent endothelial cells. Am J Physiol Heart Circ Physiol 298: H2102H2111.

17. Dawson W. (2003) Peromyscus Newsletter. No 35. Peromyscus Genetic Stock Center, Department of Biological Sciences, University of South Carolina, Columbia, SC 29208.

18. Seidler S, Zimmermann HW, Bartneck M, Trautwein C, Tacke F (2010) Age-dependent alterations of monocyte subsets and monocyte-related chemokine pathways in healthy adults. BMC Immunol 11: 30.

19. Kuranda K, Vargaftig J, de la Rochere P, Dosquet C, Charron D, et al. (2011) Age-related changes in human hematopoietic stem/progenitor cells. Aging Cell 10: 542-546.

20. Pang WW, Price EA, Sahoo D, Beerman I, Maloney WJ, et al. (2011) Human bone marrow hematopoietic stem cells are increased in frequency and myeloid-biased with age. Proc Natl Acad Sci USA 108: 20012-20017.

21. Simonetti O, Lucarini G, Cirioni O, Zizzi A, Orlando F, et al. (2013) Delayed wound healing in aged skin rat models after thermal injury is associated with an increased MMP-9, K6 and CD44 expression. Burns 39: 776-787.

22. Lowe D, Raj K (2014) Premature aging induced by radiation exhibits proatherosclerotic effects mediated by epigenetic activation of CD44 expression. Aging Cell 13: 900-910. 